\title{
AN ANALYTICAL STUDY ON LIBRARY ANXIETY OF UNDERGRADUATE STUDENTS IN ARTS \& SCIENCE COLLEGES IN TAMILNADU
}

\author{
C. ANJALINE ${ }^{1} \&$ P. SARAVANAN ${ }^{2}$ \\ ${ }^{I}$ Research Scholar, Manonmaniam Sundaranar University, Tirunellveli, India \\ ${ }^{2}$ Librarian, Lekshmipuram College of Arts and Science, Neyyoor, India
}

Library anxiety is a kind of psychological fears that users have while accessing library. It is more common among the users in academic libraries in the beginning and it reduced gradually by adapting to the library environment. This paper analyses library anxiety perceived by the undergraduate students in Arts and Science colleges. The survey was conducted among the 200 undergraduate students in Arts and Science Colleges in Kanyakumari District with respect to selected variables. The study revealed that undergraduate students have perceived library anxiety more. The study also revealed that under graduate differ significantly on library anxiety based on gender, previous experiences in using libraries and computer literacy and do not differ significantly on discipline.

KEYWORDS: Library Anxiety, Fear, Phobia, Undergraduate Students, Barriers in Library, Psychological Barriers \& Computer Literacy
\end{abstract}

Received: Jul 28, 2017; Accepted: Aug 16, 2017; Published: Sep 16, 2017; Paper Id.: IJLSRAUG20179

\section{INTRODUCTION}

Library is playing key role in the knowledge dissemination process in the higher education system. Learning environment in the higher education system, class room instructions are supplemented by the library centered teaching and learning. Self paced learning and learning for life-long learning are strategies for learning. Life-long learning skills are acquired by the user through user instruction and acquiring information literacy skills. There are several factors which influence the usage of academic libraries are fear, non-familiarity of information sources, information seeking anxiety, lack of skills in retrieving information from computer based information sources and library anxiety. Library anxiety is a major factor which influences the users among the undergraduate students at the initial stage of their college education.

\section{LIBRARY ANXIETY}

Library anxiety is described as "an uncomfortable feeling or emotional disposition, experience in a library setting, which has cognitive, affective, physiological and behavioral ramifications" (On wueghuzie, Jiao \& Bostic, 2004). Library anxiety is characterized by negative emotions including - tension, fear, feelings of uncertainty and helplessness, negative self-defeating thoughts, and mental disorganization - that are experienced in the library setting. It is kind of psychological barrier that hinder user's access to information, and has been described in broader term as information barriers. Library anxiety has a debilitating effect on a user's ability to perform library information seeking process and research performance in general. 


\section{NEED AND SIGNIFICANCE OF THE STUDY}

Library anxiety is one of the common constraints experienced by the users while using library resources and it is more at the initial stage of their college education. Adaptation to the library environment, user instruction, user orientation, imparting information literacy skills, establishing rapport with user and library professionals are the common means to overcome the barrier of library anxiety. Library anxiety is not a single factor but it is a combination of several areas namely feeling of comfortable with library, affective barriers, mechanical barriers, previous experience in use of library, relation with library professionals and so on. Several studies were conducted in developing countries on library anxiety among the users at various levels. Similarly, several tools were developed and standardized to measure library anxiety among the users at various levels. Some of the representative studies were conducted namely library anxiety among polish students (Swigon, 2011), among the college students (Bostik, 1992), Perfectionism and library anxiety among the graduate students by Jiao and Onwuegbuize (1998) and so on. Library is a common phenomenon among the users of academic libraries in India too. Scanning of available literature in library and information science shows that only few studies were conducted among the users of academic libraries. Hence, the investigator has felt the need to fill this gap and hence motivated to undertake a study to determine the library anxiety among the undergraduate students in Arts and Science Colleges.

\section{STATEMENT OF THE PROBLEM}

The present study is intends to determine library anxiety among the undergraduate students and perceived library anxiety of the undergraduate students are analyzed with respect to selected demographic variables. Hence the problem for the present study is entitled as “An Analytical Study on Library Anxiety of Undergraduate Students”.

\section{OBJECTIVES OF THE STUDY}

Objectives of the present study are

- To determine the library anxiety among the undergraduate students.

- To analyze the library anxiety among the undergraduate students with respect to (i) gender (ii) discipline (iii) previous experience in using library and (iv) Level of computer literacy.

\section{HYPOTHESES OF THE STUDY}

Hypotheses framed for the present study are

- $\quad$ Library anxiety among the undergraduate students is high in initial stage.

- There is no significant difference among the undergraduate students on their library anxiety level with respect to (i) gender (ii) discipline (iii) previous experience in using library and (iv) Level of computer literacy.

\section{LIMITATIONS OF THE STUDY}

\section{Limitations are}

- The present study is based on the responses of 200 undergraduate students of Arts and Science colleges.

- Findings of the study are confined only to undergraduate students of Arts and Science since library environment is different from Arts and Science to others. 
- Respondents of the study are limited to first and second year students only.

\section{METHODOLOGY}

The present study is intended to study the perceived library anxiety among the undergraduate students and so survey method is adopted for the study.

\section{Population of the Study}

Population for the present study is students who are undergoing undergraduate courses at various colleges in Tamilnadu.

\section{Sample for the Study}

Respondents for the present study consist of 200 undergraduate students from Arts and Science colleges of Kanyakumari district, Tamilnadu. Selection of these samples are carried out using stratified random sampling techniques by giving due representation to all categories of variables under study.

\section{Tools Used for the Study}

Tools used for the present study is adopted version standardized Library Anxiety Scale (P-LAS). Some statements are modified to the library environment. It consists of forty five statements on six dimensions namely, barriers with staff, affective barriers, technological barriers, library knowledge barriers, library comfort barriers and resource barriers. Each of these statements is rated on a five point scale of Likert type. Library anxiety of the individual are measured in terms of six dimensions of library anxiety. Low score on the statement shows the perceived anxiety is low and high value shows more library anxiety.

\section{Procedure of the Study}

Library anxiety toll was administered on a sample of 200 respondents and asked them to rate the statements on a five point scale based on their experience in the library. Positive statements are scored ' 1 ' for strongly disagree, ' 2 ' for disagree, ' 3 ' for undecided, ' 4 ' for agree and ' 5 ' for strongly agree. The same procedure is reversed for negative statements. Collected data were analyzed using the statistics tool like ' $t$ ' test and ANOVA and hypotheses are tested at 0.05 level of significant. The calculations are carried out using Software Package for Social Science (SPSS) version 17.0.

\section{ANALYSIS AND INTERPRETATION OF DATA}

\section{Distribution of Respondents Based on Demographic Variables}

The study consists of 200 respondents, 106 female students and the remaining 94 are male. Again based on the discipline, there are 100 students belongs to Arts category and the remaining 100 from Science discipline. Also, there are 109 students having previous knowledge on using various libraries and 91 have no experience. Similarly, there are 92 respondents have familiar in using computer and categorized as average in computer literacy, 40 as in above average category and 68 have poor in using computer.

\section{Library Anxiety Scores of Respondents}

Library anxiety scores among the undergraduate students are measured on six dimensions namely barriers with staff, affective barriers, technological barriers, library knowledge barriers, library comfort barriers and resource barriers. 
Average scores of total respondents on six dimensions are presented in table -1 .

Table-1: Library Anxiety Scores of the Respondents

\begin{tabular}{|c|l|c|c|}
\hline S. No & \multicolumn{1}{|c|}{ Dimensions } & Mean & S.D \\
\hline 1 & Barriers with Staff & 3.08 & 1.4 \\
2 & Affective Barriers & 3.45 & 1.5 \\
3 & Technological Barriers & 3.37 & 1.7 \\
4 & Library Knowledge Barriers & 3.26 & 1.5 \\
5 & Library Comfort Barriers & 3.18 & 1.8 \\
6 & Resource Barriers & 3.51 & 1.7 \\
\hline
\end{tabular}

Source: Primary Data

Table-1 discloses that library anxiety is prevailing among the undergraduate students and the level of anxiety is more in all dimensions except barriers with the staff and library comfort barriers. Hence, the researcher concludes that more library orientation and user friendly atmosphere in the library.

\section{Comparison of Library Anxiety Score with Respect to Gender}

Library anxiety score with respect to gender are further analyzed using $\mathrm{t}$ test. Details of analysis are given in table -2 .

Table 2: Comparison of Library Anxiety Score with Respect to Gender

\begin{tabular}{|c|c|c|c|c|c|c|}
\hline Dimensions & Gender & $\mathbf{N}$ & Mean & SD & $\mathbf{t}$ & Sig. \\
\hline \multirow{2}{*}{ Barriers with Staff } & Male & 106 & 3.34 & 1.20 & \multirow{2}{*}{$\begin{array}{c}2.43^{*} \\
p=0.01\end{array}$} & \multirow{2}{*}{ Sig. } \\
\hline & Female & 94 & 2.87 & 1.52 & & \\
\hline \multirow{2}{*}{ Affective Barriers } & Male & 106 & 3.85 & 1.24 & \multirow{2}{*}{$\begin{array}{c}2.87^{*} \\
p=0.00\end{array}$} & \multirow{2}{*}{ Sig. } \\
\hline & Female & 94 & 3.29 & 1.51 & & \\
\hline \multirow{2}{*}{ Technological Barriers } & Male & 106 & 3.75 & 1.16 & \multirow{2}{*}{$\begin{array}{c}2.51 * \\
p=0.01\end{array}$} & \multirow{2}{*}{ Sig. } \\
\hline & Female & 94 & 3.23 & 1.74 & & \\
\hline \multirow{2}{*}{ Library Knowledge Barriers } & Male & 106 & 3.83 & 1.23 & \multirow{2}{*}{$\begin{array}{c}3.15^{*} \\
p=0.00\end{array}$} & \multirow{2}{*}{ Sig. } \\
\hline & Female & 94 & 3.20 & 1.59 & & \\
\hline \multirow{2}{*}{ Library Comfort Barriers } & Male & 106 & 3.47 & 1.21 & \multirow{2}{*}{$\begin{array}{c}2.44^{*} \\
p=0.01\end{array}$} & \multirow{2}{*}{ Sig. } \\
\hline & Female & 94 & 3.06 & 1.73 & & \\
\hline \multirow{2}{*}{ Resource Barriers } & Male & 106 & 3.86 & 1.12 & \multirow{2}{*}{$\begin{array}{c}2.32 * \\
p=0.02\end{array}$} & \multirow{2}{*}{ Sig. } \\
\hline & Female & 94 & 3.38 & 1.76 & & \\
\hline
\end{tabular}

Source: Primary Data

It is clear from table-2 that there is a significant difference among the undergraduate students in library anxiety dimensions with respect to gender at 0.05 levels. Male students have more library anxiety in all dimensions than their counterparts. Hence, it is interpreted that male students have more library anxiety than female students and they are easily adaptable to the library and frequently uses the library than male students.

\section{Comparison of Library Anxiety with Discipline}

Library anxiety scores are also analyzed with respect to the discipline of the students to find out the influence of discipline on library anxiety. Details of t test are presented in table -3 .

Table 3: Comparison of Library Anxiety with Discipline

\begin{tabular}{|c|c|c|c|c|c|c|}
\hline Dimensions & Discipline & $\mathbf{N}$ & Mean & SD & $\mathbf{t}$ & Sig. \\
\hline \multirow{2}{*}{ Barriers with Staff } & Arts & 100 & 3.09 & 1.31 & \multirow{2}{*}{$\begin{array}{c}0.10 \\
p=0.91\end{array}$} & \multirow{2}{*}{ NS } \\
\hline & Science & 100 & 3.07 & 1.42 & & \\
\hline \multirow{2}{*}{ Affective Barriers } & Arts & 100 & 3.54 & 1.53 & \multirow{2}{*}{$\begin{array}{c}1.07 \\
p=0.28\end{array}$} & \multirow{2}{*}{ NS } \\
\hline & Science & 100 & 3.31 & 1.50 & & \\
\hline
\end{tabular}




\begin{tabular}{|c|c|c|c|c|c|c|}
\hline \multirow{2}{*}{ Technological Barriers } & Arts & 100 & 3.34 & 1.75 & \multirow{2}{*}{$\begin{array}{c}0.29 \\
p=0.76\end{array}$} & \multirow{2}{*}{ NS } \\
\hline & Science & 100 & 3.41 & 1.60 & & \\
\hline \multirow{2}{*}{ Library Knowledge Barriers } & Arts & 100 & 3.21 & 1.57 & \multirow{2}{*}{$\begin{array}{c}0.67 \\
p=0.67\end{array}$} & \multirow{2}{*}{ NS } \\
\hline & Science & 100 & 3.3 & 1.48 & & \\
\hline \multirow{2}{*}{ Library Comfort Barriers } & Arts & 100 & 3.16 & 1.62 & \multirow{2}{*}{$\begin{array}{c}0.17 \\
p=0.85\end{array}$} & \multirow{2}{*}{ NS } \\
\hline & Science & 100 & 3.20 & 1.54 & & \\
\hline \multirow{2}{*}{ Resource Barriers } & Arts & 100 & 3.55 & 1.61 & \multirow{2}{*}{$\begin{array}{c}0.29 \\
p=0.76\end{array}$} & \multirow{2}{*}{ NS } \\
\hline & Science & 100 & 3.48 & 1.73 & & \\
\hline
\end{tabular}

Source: Primary Data, NS- Not significant

Table 3 reveals that discipline has no influence on the library anxiety among the undergraduate students. Calculated value of $t$ is not significant at any level. Hence the researcher concludes that there is no significant difference among the undergraduate students on library anxiety with respect to discipline.

\section{Comparison of Library Anxiety with Previous Experience}

Library anxiety among the students is positively as well as negatively influenced by their experience in using library as well as their aware of library formalities and their information literacy level. Library anxiety score is further compared with their previous experience on library.

Table 4: Comparison of Library Anxiety with Previous Experience

\begin{tabular}{|c|c|c|c|c|c|c|}
\hline Dimensions & Prev. Exp & $\mathbf{N}$ & Mean & SD & $\mathbf{t}$ & Sig. \\
\hline \multirow{2}{*}{ Barriers with Staff } & Yes & 109 & 3.03 & 1.43 & \multirow{2}{*}{$0.40 p=0.63$} & \multirow{2}{*}{ NS } \\
\hline & No & 91 & 3.11 & 1.32 & & \\
\hline \multirow{2}{*}{ Affective Barriers } & Yes & 109 & 3.08 & 1.53 & \multirow{2}{*}{$2.3 * p=0.02$} & \multirow{2}{*}{ Sig. } \\
\hline & No & 91 & 3.56 & 1.38 & & \\
\hline \multirow{2}{*}{ Technological Barriers } & Yes & 109 & 3.23 & 1.70 & \multirow{2}{*}{$1.01 p=0.31$} & \multirow{2}{*}{ NS } \\
\hline & No & 91 & 3.47 & 1.64 & & \\
\hline \multirow{2}{*}{ Library Knowledge Barriers } & Yes & 109 & 3.2 & 1.60 & \multirow{2}{*}{$0.50 p=0.61$} & \multirow{2}{*}{ NS } \\
\hline & No & 91 & 3.31 & 1.46 & & \\
\hline \multirow{2}{*}{ Library Comfort Barriers } & Yes & 109 & 3.07 & 1.64 & \multirow{2}{*}{$0.80 p=0.4$} & \multirow{2}{*}{ NS } \\
\hline & No & 91 & 3.25 & 1.52 & & \\
\hline \multirow{2}{*}{ Resource Barriers } & Yes & 109 & 3.11 & 1.90 & \multirow{2}{*}{$\begin{array}{c}2.15^{*} \\
p=0.03\end{array}$} & \multirow{2}{*}{ Sig. } \\
\hline & No & 91 & 3.66 & 1.61 & & \\
\hline
\end{tabular}

Source: Primary Data, Sig.- Significant, NS - Not Significant

Table 4 discloses that previous experience on library has significantly influenced the library anxiety on the dimensions namely affective barriers and resource barriers at 0.05 levels among the undergraduate students and it is not significant with other dimensions. Hence the researcher interpreted that there is more stress on library orientation as well as information awareness and literacy.

\section{Comparison of Library Anxiety with Computer Literacy}

Based on the computer literacy, respondents are classified into three groups namely below average, Average in handling computer and above average. There are 68 respondents have the computer literacy below average, 92 with average and 40 have above average on computer literacy. Analysis of variance is conducted to find the significant difference if any in their library anxiety. Details of ANOVA are summarized in table 5. 
Table 5: Comparison of Library Anxiety with Computer Literacy

\begin{tabular}{|c|c|c|c|c|c|c|}
\hline Dimensions & & Sum of Squares & df & Mean Square & $\mathbf{F}$ & Sig. \\
\hline \multirow{2}{*}{ Barriers with Staff } & Between Groups & 1.606 & 2 & .803 & \multirow{2}{*}{$6.399 *$} & \multirow{2}{*}{.002} \\
\hline & Within Groups & 12.169 & 197 & .125 & & \\
\hline \multirow{2}{*}{ Affective Barriers } & Between Groups & .941 & 2 & .470 & \multirow{2}{*}{1.742} & \multirow{2}{*}{.181} \\
\hline & Within Groups & 26.191 & 197 & .270 & & \\
\hline \multirow{2}{*}{ Technological Barriers } & Between Groups & 3.878 & 2 & 1.939 & \multirow{2}{*}{$4.550 *$} & \multirow{2}{*}{.013} \\
\hline & Within Groups & 41.340 & 197 & .426 & & \\
\hline \multirow{2}{*}{$\begin{array}{l}\text { Library Knowledge } \\
\text { Barriers }\end{array}$} & Between Groups & 3.319 & 2 & 1.659 & \multirow{2}{*}{$6.678^{*}$} & \multirow{2}{*}{.002} \\
\hline & Within Groups & 24.102 & 197 & .248 & & \\
\hline \multirow{2}{*}{$\begin{array}{l}\text { Library Comfort } \\
\text { barriers }\end{array}$} & Between Groups & 1.736 & 2 & .868 & \multirow{2}{*}{2.650} & \multirow{2}{*}{.076} \\
\hline & Within Groups & 31.777 & 197 & .328 & & \\
\hline \multirow{2}{*}{ Resource Barriers } & Between Groups & 4.347 & 2 & 2.173 & \multirow{2}{*}{$5.048 *$} & \multirow{2}{*}{.008} \\
\hline & Within Groups & 41.759 & 197 & .431 & & \\
\hline
\end{tabular}

Source: Primary Data

Table 5 reveals that computer literacy of the students have significant difference on the library anxiety with respect to the dimension namely barriers with staff, technological barriers, Library knowledge barriers and resource barriers at 0.05 level and it is not significant on other dimensions

\section{FINDINGS OF THE STUDY}

Findings of the Study are

- Library anxiety is exists among the undergraduate students and the level is above average.

- There is a significant difference exists among the undergraduate students on the library anxiety with gender.

- There is no significant difference among the undergraduate students on the library anxiety with discipline.

- Significant difference exists among the undergraduate students on library anxiety with previous knowledge on affective and resource barriers.

- Significant difference exists among the undergraduate students on barriers with staff, technological barriers, library knowledge barriers and resource barriers at 0.05 levels.

\section{CONCLUSIONS}

The present study shows that library anxiety exists among the undergraduate students at the beginning stage. Proper library orientation, awareness on use of library, user instruction, computer literacy and good rapport with the library professionals are the means to overcome library anxiety among the students and it should be reduced to minimum on later stage.

\section{REFERENCES}

1. Bostick, S.L. (1992). The development and validation of the library anxiety scale. Dissertation Abstracts International, 53-12, A4116.

2. Jiao Q.C. and Onwuegbuize, A. J. (1998). Perfectionsm and library anxiety among the graduate students, Journal of Academic Librarianship. 24, 365-71.

3. Swigon, M. (2011). Library anxiety among polish students: Development and validation of Polish library anxiety scale. Library and Information Science Research, 33(10), 144-150. 